TITLE:

\title{
Dependence of the precipitation intensity in mesoscale convective systems to temperature lapse rate
}

\author{
AUTHOR(S): \\ Takemi, Tetsuya
}

CITATION:

Takemi, Tetsuya. Dependence of the precipitation intensity in mesoscale convective systems to temperature lapse rate. Atmospheric Research 2010, 96(2-3): 273-285

ISSUE DATE:

2010-05

URL:

http://hdl.handle.net/2433/128899

RIGHT:

(c) 2009 Elsevier B.V.; この論文は出版社版でありません。引用の際には 出版社版をご確認ご利用ください。; This is not the published version. Please cite only the published version. 


\title{
Dependence of the Precipitation Intensity in Mesoscale Convective Systems to Temperature Lapse Rate
}

\author{
Tetsuya Takemi \\ Disaster Prevention Research Institute, Kyoto University, Gokasho, Uji, Kyoto \\ 611-0011, Japan
}

\begin{abstract}
The dependence of the structure and intensity of precipitation generated within squall lines to environmental temperature lapse rate is investigated by the use of a large set of numerical experiments under idealized model configurations. The lapse rate in a convectively unstable layer is used for the present analysis. The mean precipitation intensity during the simulated period generally increases with the increase in lapse rate, while the maximum precipitation intensity increases with the decrease in lapse rate. The precipitation mean is dependent on the intensity of cold pool resulting from organized convective clouds. In contrast, the precipitation maxima is regulated by relative humidity within the tropospheric lower layer. In an environment with higher lapse rate, a larger amount of CAPE is distributed in a deeper layer of the lower troposphere, which is beneficial for the development and intensification of convection and precipitation. Lapse rate in the troposphere is useful in comparing the characteristics of precipitation produced by mesoscale convective systems that occur in various climate regions of the world and also produced in a future climate under global warming. Key words: Precipitating cloud systems, Cumulus convection, Cloud
\end{abstract}

Email address: takemi@storm.dpri.kyoto-u.ac.jp (Tetsuya Takemi) 
dynamics, Static stability

\section{Introduction}

The structure and intensity of mesoscale convective systems (MCSs) are strongly regulated by their environmental conditions such as horizontal wind, temperature, and moisture. These environmental conditions reflect synopticscale meteorological phenomena that are characterized by diverse climates ranging from the Tropics, subtropical regions, arid and semi-arid regions, and the midlatitude regions. The intensity of convectively induced precipitation is directly controlled by the structure, organization, and intensity of MCSs and thus can be related to and diagnosed by those environmental conditions. Vertical wind shear determines the structure and organization of MCSs and hence their intensity, while temperature and moisture conditions characterize static stability that would control the development and maintenance of MCSs.

The effects of vertical wind shear on the structure and strength of MCSs have been investigated through observational, modeling, and theoretical studies. It is understood that the dynamical interaction between vertical shear and evaporatively induced cold pool is an important mechanism in controlling the strength and longevity of MCSs, specifically squall lines (Thorpe et al., 1982; Rotunno et al., 1988; Weisman et al., 1988; Fovell and Ogura, 1989; Robe and Emanuel, 2001; Weisman and Rotunno, 2004). Although there is an argument on how the shear affects the MCS structure and intensity (Lafore and Moncrieff, 1989; Rotunno et al., 1990; Weisman and Rotunno, 2004), it is recognized that the interaction between vertical shear and cold pool plays a significant role.

In contrast, there are still unknowns on the effects of temperature and 
moisture profiles on the structure, evolution, and strength of MCSs. These variables determine the thermodynamic environments that can be diagnosed by various stability parameters and indices (e.g. Bluestein, 1993; Emanuel, 1994). Using the thermodynamic parameters and stability indices, a number of studies examine the thermodynamic environments for MCSs and rainstorms that occur in various climate regions: the United Stated (Bluestein and Jain, 1985; Houze et al., 1990; Cohen et al., 2007); the Tropics (Barnes and Sieckman, 1984; LeMone et al., 1998); and the subtropical regions (Wang et al., 1990). However, it is very difficult to determine a universal standard for the diagnosis of the development of MCSs by use of a single stability index or some combination of the indices. This is partly because MCSs develop under various synoptic-scale to micro-scale external forcings. The other reason is that there is a large number of degrees of freedom in determining the profiles of temperature and moisture. For example, even though stability indices are the same among different environments, the shape of the temperature and moisture profiles, which would change the development and organization of MCSs, can be different. In order to understand factors that control the structure and strength of MCSs in various environmental conditions, conducting a systematic set of numerical experiments is a useful tool to examine the sensitivity of MCSs to the temperature and moisture profiles. Considering that the temperature condition largely differs among the various climatological regions, a sensitivity to temperature profile should be clarified.

Recently there are studies that investigate sensitivities to the temperature conditions by carefully setting temperature and moisture profiles. McCaul et al. (2005) examined numerically the sensitivity of supercell storms to environmental temperature by changing only the temperature at the lifting 
condensation level with convective available potential energy (CAPE) and other environmental parameters being fixed. They found that updraft speed and precipitation efficiency are higher in a colder environment, while the peak precipitation rate in a warmer environment is comparable to that in the colder environment. James et al. (2006) conducted a number of numerical experiments by changing low-level moisture contents and tropospheric temperatures but maintaining CAPE values and showed that in a warmer (colder) environment a weaker (stronger) cold pool is produced and hence the scale of convective cells becomes smaller (larger). Houston and Niyogi (2007) examined how the temperature lapse rate above the level of free convection (LFC) affects the development of cumulus convection by performing numerical experiments and indicated that stronger convection is produced in conditions with a larger temperature lapse rate. Takemi (2007a) investigated numerically the effects of static stability on the squall-line intensity by systematically changing temperature lapse rate with CAPE being unchanged. He showed that a colder environment (which is more unstable) is favorable for generating stronger cold pool, which will highly control the scale and strength of convective updrafts and hence the organization and intensity of squall lines. There is, however, still a remaining issue as to how the characteristics of cloud and precipitation depend on environmental temperature profile.

In the present study, therefore, with the use of the simulated dataset in Takemi (2007a), we examine the structure and intensity of precipitation generated within the squall lines under different temperature conditions. The numerical experiments were conducted in idealized settings in order to focus on the convective dynamics. Squall lines that develop in line-perpendicular, low-level vertical shear are specifically emphasized, since the low-level shear 
affects most significantly the structure and intensity of squall lines among shears at other height levels (Rotunno et al., 1988; Weisman and Rotunno, 2004). The sensitivity indicated by the numerical experiments is interpreted with the use of a stability parameter. In addition, we discuss the characteristics of precipitation due to convective systems in a future climate with anticipated global warming.

\section{Numerical model and experimental design}

The numerical model used for the sensitivity experiments is the Advanced Research WRF (Weather Research and Forecasting) model, Version 2.1.2 (Skamarock et al., 2005), which is a non-hydrostatic, compressible atmospheric model developed mainly at National Center for Atmospheric Research in the United States. Although the detailed model setup can be found in Takemi (2007a), it is briefly described here for the readers' convenience.

The WRF model is configured in idealized settings with no Coriolis force, no surface fluxes, no atmospheric radiation, and no horizontal variability in basic states. The physics parameterizations included here are cloud microphysics (Hong and Lim, 2006) and turbulence mixing (Deardorff, 1980). The microphysics parameterization employed here is the most sophisticated single-moment scheme in the WRF version 2.1.2. This scheme solves the prognostic equations for the mixing ratios of water variables, i.e., water vapor, cloud water, rainwater, cloud ice, snow, and graupel, by including the formulations of water/ice conversion processes (Lin et al., 1983) with a revised approach in computing the processes relevant to the formation of cloud ice (Hong et al., 2004). This bulk-type scheme including ice phase is considered to be appropriate to the reproduction of realistic storm behavior in idealized numerical simulations (Fovell and Ogura, 1988). The turbulence 
mixing scheme, on the other hand, solves a prognostic equation of turbulent kinetic energy to be used for computing the eddy viscosity coefficients both in the horizontal and the vertical directions.

These settings may seem to be too idealized to compare with real cases, but the idealized settings are useful in identifying the essential dynamics of convective processes and have been successfully employed in previous studies (e.g. Rotunno et al., 1988; Weisman et al., 1988; Weisman and Rotunno, 2004). The model domain is $300 \mathrm{~km}$ (east-west) by $60 \mathrm{~km}$ (north-south) by $17.5 \mathrm{~km}$ (vertical) with an open condition at the eastern and western lateral boundaries and the periodic condition at the north and south boundaries. The horizontal grid spacing is $500 \mathrm{~m}$ and the vertical grid number is 70 .

The model is initialized with horizontally homogeneous states by specifying the vertical profiles of temperature, moisture, and horizontal wind. The temperature and moisture profiles are determined by the use of the analytic function of Weisman and Klemp (1982). Environmental potential temperature $\theta_{\text {env }}$ and relative humidity $R H$ in the troposphere are given as follows:

$$
\theta_{\text {env }}(z)=\theta_{0}+\left(\theta_{t r}-\theta_{0}\right)\left(z / z_{t r}\right)^{5 / 4}
$$

and

$$
R H(z)=1-0.75\left(z / z_{t r}\right)^{5 / 4}
$$

where $z_{t r}(=12 \mathrm{~km})$ is the tropopause height, $\theta_{t r}$ represents potential temperatures at the tropopause, and $\theta_{0}(=300 \mathrm{~K})$ potential temperature at the surface. In Weisman and Klemp (1982) $\theta_{t r}$ is fixed at $343 \mathrm{~K}$ in order to represent a typical condition for convective storms over the continental plains in the United States. By changing the value of $\theta_{t r}$, various temperature environments can be defined. Here we set the $\theta_{t r}$ value at $343,348,353$, and 358. 
Figure 1 shows the vertical profiles of potential temperature for the four $\theta_{t r}$ cases. The profiles of the United States Standard Atmosphere and obtained from the observations during active convective periods in the tropical western Pacific (Yoneyama, 2003; Takemi et al., 2004) are also plotted for comparison. The $\theta_{t r}$ values examined here mostly fall into the range of tropical and midlatitude regions, and therefore the sensitivity to temperature lapse rate under various conditions can be investigated. The tropospheric moisture content above the $1.5-\mathrm{km}$ height is calculated with the definition of (2), while the moisture content below the $1.5-\mathrm{km}$ height $\left(q_{v 0}\right)$ is fixed at a constant water vapor mixing ratio. The value of $q_{v 0}$ is chosen in order to keep CAPE for the surface air parcel maintained with different $\theta_{t r}$ values. Table 1 summarizes the list of the numerical experiments, which is the same as in Takemi (2007a) except for the control experiment. Note that precipitable water content increases with the increase in $\theta_{t r}$.

The values of CAPE for the surface air parcel are calculated by integrating the buoyancy of a parcel originated at the lowest model level from LFC to the level of neutral buoyancy (LNB). The buoyancy here is defined by the use of base-state and anomaly values of virtual potential temperature. The vertical profiles of buoyancies for surface parcels in the different $\theta_{t r}$ cases are exhibited in Fig. 2. The shape of the buoyancy profile and the overall values of buoyancy look similar with each other, which suggests that all the environments have similar potential for strong convection. There are, however, noticeable differences in LFC/LNB and the buoyancy maximum among the profiles. LFC (and also CIN) becomes lower and as the value of $\theta_{t r}$ increases, and in addition the shape of buoyancy is almost the same; this would lead to a larger value of total buoyancy integrated from LFC to at least the 5 -km level. What is suggested from these differences is that stronger 
updrafts would be generated in the lower half of the troposphere in a higher $\theta_{t r}$ case. This point is discussed in Section 3.3, after presenting the results of the numerical experiments.

From the previous studies (Weisman and Rotunno, 2004; Takemi, 2007b), low-level shear plays a profound role in determining the intensity of squall lines. Therefore, shears in the lowest atmospheric layer are examined for each case with its defined thermodynamic properties listed in Table 1 . We examine two types of low-level shears: a weaker one and a stronger one which are shown in Fig. 3. The total number of numerical experiments presented in this study thus amounts to 24 .

The initialization procedure for the numerical experiments is the same as in Takemi (2007a), which follows the method of Rotunno et al. (1988) and Weisman et al. (1988). Linear elliptical thermal oriented in the north-south direction is placed at the lowest layer. Therefore, we assume squall lines as an MCS in the present study. The simulation period is 4 hours, and the analyses are made for model outputs at 5-min interval.

\section{Results}

\subsection{Precipitation structure and intensity}

The overall characteristics of squall-line structure have been documented in Takemi (2007a); in this paper the structure and intensity of precipitation within the squall-line system are mainly described.

Figure 4 shows the horizontal distributions of total water condensation mixing ratio (i.e., the sum of the mixing ratios of cloud water, cloud ice, rainwater, snow, and graupel) at the $3-\mathrm{km}$ height for the different $\theta_{t r}$ values in the C17 series with the weak shear. Cloud cells are generated behind a surface cold pool. As the value of $\theta_{t r}$ decreases (i.e., larger temperature 
lapse rate), the area of a significant amount of condensation mixing ratio becomes wider and a cellular structure elongated rearward becomes more evident. This type of elongated cellular feature was identified by Weisman and Rotunno (2004) in their no-shear experiment, in which the cold-pool forcing dominates the shear effect and hence the effects of linear organization perpendicular to the shear direction are minimized. The spatial distribution results in more total precipitation with a lower $\theta_{t r}$ value. The comparison of the cloud and precipitation field with the vertical velocity field for the weak-shear cases (Fig. 5) indicates that the enhanced mixing ratios of water condensation are generated by updrafts nearer to the leading edge of the cold pool and by both updrafts and downdrafts rearward of the convective system.

With the strong shear, the difference among the different $\theta_{t r}$ cases becomes more distinguishable (Fig. 6). As in the weak-shear cases, the area of higher condensation mixing ratios extends wider with the decrease in $\theta_{t r}$. The organization as a convective line in the cases of $\theta_{t r}=343$ and 348 is more evident than in those with the weak shear. This is because the interaction between the cold pool and the strong shear works more effectively in these $\theta_{t r}$ cases (Rotunno et al., 1988). Actually, the intensities of the cold pools in those $\theta_{t r}$ cases, defined as a scaled velocity corresponding to the integrated negative buoyancy within the cold pools, were comparable to the difference of wind speed in the shear layer (Takemi, 2007a). Thus, stronger and more erect updrafts are generated at the leading edge of the cold pool in the strong-shear cases than in the weak shear. This results in the production of higher mixing ratios near the leading edge of the cold pool in the strong shear. These features further lead to the increase in total precipitation with the decrease in $\theta_{t r}$. 
In Fig. 6, it appears that the convective cells in the higher $\theta_{t r}$ cases (especially with $\theta_{t r}=358$ ) have a similarity with supercell storms or bowshaped segments in squall lines (e.g. Weisman and Rotunno, 2004). However, the updraft speeds within the cells are too low (i.e., lower than those in the lower $\theta_{t r}$ cases) to be identified as a supercell. What the bow-shaped segments actually indicate here is a disorganized feature of the simulated squall line.

It should be noted that the peak values of the mixing ratio in Figs. 4 and 6 seem to be almost the same among the different $\theta_{t r}$ cases with the identical shear. Figure 7 compares the temporal variation of the domain maxima of the total cloud and precipitation mixing ratio for the weak-shear and strong-shear cases. It is indicated that in general the maximum values are nearly the same among the different $\theta_{t r}$ cases and no significant tendency with the $\theta_{t r}$ value can be identified. This feature clearly contrasts with the spatial appearances of the cloud and precipitation field shown in Figs. 4 and 6. This point will be discussed later in relation to the precipitation maxima in Section 3.2.

As indicated in Takemi (2007a), the decrease of $\theta_{t r}$ results in a larger scale of updraft cells. A larger area of updraft cells will induce more condensation and hence more cloud and precipitation content within the convective system. Here, the vertical motion field is examined by the total area of updrafts and downdrafts within an analysis area having a dimension of $50 \mathrm{~km}$ by $60 \mathrm{~km}$ defined as follows: the east boundary of the analysis area is at $10 \mathrm{~km}$ ahead of the mean location of the leading edge of cold pool; and the west boundary is set at $40 \mathrm{~km}$ behind the cold-pool leading edge. This analysis area is chosen because it covers the main region of cloud and precipitation within the simulated squall lines as shown in Figs. 4 and 6. Stronger and weaker updrafts/downdrafts are defined as the velocity being larger than $1.0 \mathrm{~m} \mathrm{~s}^{-1}$ 
(based on the work of LeMone and Zipser (1980)) and between 0.1-1.0 $\mathrm{m} \mathrm{s}^{-1}$, respectively. At all the output times (i.e., 5-min interval) the maximum values are calculated.

Figure 8 compares the vertical profiles of the fractional area of strong updrafts and downdrafts at each model level over the analysis area for the weak-shear C17 cases. The profiles are averaged in time during the period of 1-4 h. The fractional area of strong updrafts/downdrafts becomes significantly larger with the decrease of $\theta_{t r}$. On the other hand, the fractional area for the weak vertical velocity indicates a less organized feature, but it does show the tendency toward wider area with $\theta_{t r}$ decreased (Fig. 9). Consequently, the total area of strong and weak updraft/downdraft is wider in a lower $\theta_{t r}$ case, which seems to be consistent with the precipitation distribution shown in Fig. 4. The same features were also identified in the strong-shear cases, which indicated more pronounced difference among the cases (not shown): a consistent feature with what is shown in Fig. 6.

The locations of higher values of condensation mixing ratio are found in and around significant updrafts and downdrafts (e.g., compare Figs. 4 and 5 for the weak-shear cases). Therefore, the rain fields are examined for updraft/downdraft cores that are represented by vertical velocities greater than $1.0 \mathrm{~m} \mathrm{~s}^{-1}$. Figure 10 indicates the vertical profiles of rainwater mixing ratio at strong updraft grids at each model level for the C17 cases. The temporal averages of the spatial means and maxima over the analysis area during 1-4 h are plotted. In contrast to the profiles of the updraft/downdraft fractional area, the rainwater content in the lowest $\theta_{t r}$ case is not the highest among the various $\theta_{t r}$ values. On the contrary, it is seen that the rainwater content tends to be higher in warmer environments (i.e., higher $\theta_{t r}$ ). The most notable point is that in the strong shear cases the maximum rainwater 
content is actually highest at all the levels in the case $\theta_{t r}=358$, although the precipitation and updraft area is significantly smaller in this highest $\theta_{t r}$ case than the other $\theta_{t r}$ cases.

For the strong downdraft grids, on the other hand, the characteristics of the rainwater profiles appear to be less clear and less organized (Fig. 11). For example, it is seen that the lowest $\theta_{t r}$ case does not necessarily indicate the highest rainwater mixing ratio. Actually, the highest rainwater mixing ratio near the ground level is found for the case $\theta_{t r}=358$. In other words, within strong downdraft cores the rain intensity becomes higher as the lapse rate decreases. Note that the area of the cloud and precipitation (Figs. 4 and 6) as well as the strong updraft/downdraft (Fig. 8) is significantly smaller in the lowest lapse rate case. This suggests that the mean and the peak precipitation behave differently; this point is further discussed in the next subsection.

The examination of the rainwater distribution at the weak updraft/downdraft grids indicated that there was no clear relationship between rainwater mixing ratio and $\theta_{t r}$ (not shown). Overall, rainwater mixing ratios were significantly smaller at the weak updraft/downdraft grids than in the strong velocity cores. Since a smaller amount of rainwater results in weaker precipitation at the ground, it is indicated that there is only a minor contribution of rain content within the weak drafts to the total amount of surface precipitation. This is consistent with the fact that the distribution of higher precipitation intensity mostly determines the total precipitation within the squall lines (Takemi, 2006). Thus, the distribution of rainwater within the strong updraft/downdraft shown in Figs. 10 and 11 is important for considering the precipitation characteristics and therefore is used for the later discussion. 


\subsection{Sensitivity to temperature lapse rate}

The characteristics of the structure and intensity of precipitation in the squall-line system shown in the previous subsection are reorganized in terms of temperature lapse rate. Takemi (2007b) showed that the squall-line intensity is well delineated in terms of temperature lapse rate and Takemi (2007a) further explored the use of the lapse rate in a set of sensitivity experiments. As in Takemi (2007b), we use lapse rate $\Gamma$ within a convectively unstable layer (i.e., a layer in which the vertical gradient of equivalent potential temperature is negative, corresponding to almost the lower half of the troposphere) defined as follows:

$$
\Gamma=\frac{T_{z\left(\theta_{e \min }\right)}-T_{z\left(\theta_{e \max }\right)}}{z\left(\theta_{e \min }\right)-z\left(\theta_{e \max }\right)}
$$

where $T_{z\left(\theta_{\text {emax }}\right)}$ and $T_{z\left(\theta_{e \min }\right)}$ are temperatures at the levels with equivalent potential temperature maximum $\theta_{e \max }$ and minimum $\theta_{e m i n}$, respectively. All the simulated cases listed in Table 1 are linked to this temperature lapse rate.

The cold pool produced by precipitation evaporation is an important ingredient for the organization and dynamics of squall lines (Rotunno et al., 1988; Robe and Emanuel, 2001; Weisman and Rotunno, 2004; James et al., 2005). The intensity of the cold pool is therefore examined in relation to temperature lapse rate. The cold-pool intensity is defined as in Rotunno et al. (1988) and calculated as in Takemi (2007a,b). It represents the average of the negatively buoyant energy within the cold pool near its leading edge and has a unit of velocity. Means and standard deviations from the time series of the cold-pool intensity during the period of 1-4 h are calculated for all the simulated cases. Figure 12 exhibits the variability of the cold-pool intensity against the temperature lapse rate for the weak-shear and the strong-shear cases.

The intensity of cold pools generally depends on the organization of con- 
vective systems and on the environmental conditions (especially the humidity environment). Two tendencies are identified in Fig. 12: the increase in coldpool intensity with the increase in lapse rate at a fixed CAPE value and the increase in cold-pool intensity with the increase in CAPE at a similar lapse rate. The first tendency seems to be resulted mainly from the surface dryness (see Table 1) which promotes the evaporative cooling of precipitation. This was confirmed by the fact that the potential temperatures in the lower layer decreased within the strong downdraft cores as $\theta_{t r}$ decreased (not shown here; see Fig. 15a of Takemi, 2007a).

On the other hand, the second tendency is related more to the degree of the organization of the simulated squall lines rather than to the environmental humidity. The cold pool becomes more intense with the increase in CAPE, in spite of a moister condition in the lower layer. Actually, the total amount of condensation within the squall-line system was significantly smaller in the C10 series than in the higher CAPE cases (not shown). What is indicated here is that a significant amount of condensation should be required before the generation of precipitation and hence the activation of evaporative cooling. If only an insufficient amount of condensation occurs within a squall line, a drier condition performs negatively on the intensity of the cold pool. In Takemi (2006) it was shown that a higher moisture condition is more favorable for the intensification of squall lines and their cold pools at the same temperature environment (i.e., the same lapse rate). Therefore, the reason why a higher lapse rate is favorable for producing a stronger cold pool is firstly because there occurs active development of cloud and precipitation to activate precipitation evaporation and secondly because a drier surface condition promotes the evaporative cooling.

From the model outputs at the 5-min interval (during the period of 1-4 
h), the means and maxima of precipitation intensity at the surface in the analysis area of $50 \mathrm{~km}$ by $60 \mathrm{~km}$ are calculated. These two parameters are then averaged in time to calculate the temporal means and standard deviations which are shown in Fig. 13 for the weak-shear cases. The mean precipitation intensity increases with the increase in lapse rate at a fixed CAPE value and also increases with the increase in CAPE among fixed $\theta_{t r}$ cases, which are similar to the features for the cold-pool intensity shown in Fig. 12. On the other hand, the maximum precipitation intensity indicates the opposite sense: the maxima increase with the decrease in lapse rate if CAPE is fixed at a constant value. There is a peak of the maxima at around $6.4 \mathrm{~K} \mathrm{~km}^{-1}$. Below this lapse rate, the maxima sharply decreases with the further decrease in lapse rate. This is due to a less organized structure of the convective systems. As a matter of course, the value of 6.4 itself is not a universal parameter. What is more important here is that there exists an optimal lapse rate for developing precipitation maxima.

As shown in Fig. 11, rainwater content near the surface within the strong downdrafts is the highest in the warmest case (i.e., the lowest lapse rate). This is because in a warmer case (i.e., lower lapse rate) the low-level environment is moister (see Table 1) and therefore precipitation within the downdrafts experiences less evaporation. In this way, instantaneous precipitation intensity will be higher in cases with lower lapse rate. It is important to note that this is true after a sufficient amount of cloud and precipitation is generated. In this sense, a certain amount of CAPE (and hence moisture) that is sufficient for developing organized convective systems is required. With less organization of convective clouds, the precipitation maxima sharply decreases for the C10 warmest case as compared with the higher CAPE cases. These opposing factors are considered to contribute a peak value of lapse 
rate for the precipitation maxima.

The same characteristics can be seen for the strong-shear cases (Fig. 14). The variability becomes larger and the sensitivity to CAPE becomes more significant. It is seen that a warmer environment (i.e., lower lapse rate) is favorable for producing higher precipitation maxima; however, this is true with $\mathrm{CAPE} \geq 1700$. Again, this suggests that the development and organization of convective clouds is at first necessary.

Table 2 summarizes the time-mean percentages of precipitation areas with the intensities of greater than $1 \mathrm{~mm} \mathrm{~h}^{-1}$ (total precipitation) and of greater than $10 \mathrm{~mm} \mathrm{~h}^{-1}$ (intense precipitation) over the defined analysis area during 1-4 h. The precipitation area increases with the decrease in $\theta_{t r}$ at a fixed CAPE while it decreases with the decrease in CAPE at an identical $\theta_{t r}$. This behavior is similar to those identified in the cold-pool intensity and in the mean precipitation. Therefore, it can be said that stronger cold pool and wider precipitation area lead to higher precipitation on average. In particular, the amount of mean precipitation depends more on the horizontal extent of the intense precipitation.

It should be noted that despite a lower precipitable water content in case of a higher lapse rate at fixed CAPE the mean precipitation becomes higher. In other words, precipitation efficiently occurs in an environment of a higher lapse rate but with less available moisture. It was shown that well-developed cold pool was generated in cases with higher lapse rates (Fig. 12). This also suggests that the development of an organized convective structure including cold pool is important in producing a significant amount of total precipitation in cases of lower CAPE values. Without the convective organization, high precipitable water content will not be beneficial to the precipitation production. In cases with fixed $\theta_{t r}$, on the other hand, the mean precipitation 
increases with the increase in both CAPE and precipitable water content. This is quite reasonable and was demonstrated in the set of numerical experiments changing humidity profile under an identical temperature condition (Takemi, 2006).

\subsection{Importance of the vertical distribution of CAPE}

The numerical experiments for the series of cases with fixed CAPE showed that the simulated convective system is more organized and the precipitation production is larger in a lower $\theta_{t r}$ case (i.e., higher lapse rate) despite a lower precipitable water. From Figure 2, it is indicates that the distribution of buoyancy for surface parcel does not significantly differ among the different $\theta_{t r}$ cases. It was even suggested that a higher $\theta_{t r}$ case would spawn stronger updraft, which actually is not consistent with the present numerical results. Therefore, the stability properties of parcels originated only at the surface seems not to provide a useful diagnosis of the intensity of convection in different temperature environments.

In this study, the seemingly contradictory result, that is, stronger convection under lower moisture environment at similar CAPE, is interpreted by examining the vertical distribution of CAPE. Takemi and Satomura (2000) insisted that the vertical distribution of CAPE within the planetary boundary layer is critical for the development and maintenance of squall lines under drier conditions. This idea is applied for the present study.

Figure 15 presents the distribution of CAPE for air parcels originating at each height in the lower atmosphere. For all the CAPE series, the CAPE values in the lowest levels including at the surface are almost the same among the different $\theta_{t r}$ cases; however, the depths of constant CAPE are largely different. The layer of constant CAPE is deeper in a lower $\theta_{t r}$ case. With the deeper layer of sufficient CAPE, air parcels not only at the surface but 
also in the boundary layer have a potential to become strong updrafts after being lifted above their levels of free convection. Even if available moisture (i.e., precipitable water) is less, a deeper layer with significant CAPE is favorable for the development and intensification of squall lines and resultant precipitation. The behavior presented previously in this section can therefore be explained by the vertical distribution of CAPE.

A deep layer of sufficient CAPE can be realized in environments with a higher lapse rate in the troposphere, especially in the lower troposphere, as well as a certain amount of water vapor in the boundary layer. To put it other way, the effects of both tropospheric lapse rate and boundary-layer moisture content are integrated into the distribution of CAPE for air parcels originating in the lower atmosphere. The importance of the CAPE distribution is manifested evidently in lower CAPE environments than in higher CAPE cases, supporting the idea of Takemi and Satomura (2000). The vertical distribution of CAPE is also recognized to play an important role in the mechanisms for the maintenance and evolution of nocturnal convective systems (Parker, 2008).

\section{Conclusions and discussion}

We have investigated the dependence of the precipitation structure and intensity within the squall lines to environmental temperature lapse rate by using a large set of the simulation dataset of Takemi (2007a). The numerical experiments were designed in order to compare the simulated squall lines under identical CAPE conditions by systematically changing lapse rate. The results are interpreted in terms of the lapse rate in a convectively unstable layer (Takemi, 2007b) and the vertical distribution of CAPE (Takemi and Satomura, 2000). 
The temporal and spatial mean precipitation intensity (which is the same as the accumulated precipitation) generally increases with the increase in lapse rate. CAPE for an air parcel originating at the surface can be a good measure for evaluating the mean precipitation if the lapse rates among the different conditions are similar. What is actually critical is the vertical distribution of CAPE for air parcels originating in the lower atmosphere. The CAPE distribution is closely tied to the lapse rate in the troposphere as well as the moisture content in the boundary layer. On the other hand, the maximum precipitation intensity indicates an opposite sense: the maxima increases with the decrease in lapse rate. There may be an optimal lapse rate for developing precipitation maxima. The precipitation accumulation is dependent on the intensity of cold pool that results from the organized structure of a convective system. In contrast, the precipitation maxima is regulated by relative humidity within the tropospheric lower layer where precipitation is falling: higher relative humidity is beneficial for enhancing surface precipitation intensity owing to the smaller effect of evaporation.

The parameters presented in this study, the temperature lapse rate in a convectively unstable layer and the vertical distribution of CAPE, are applicable for comparing the precipitation characteristics produced by MCSs that occur in various climate regions of the world. The lapse rate should be more useful in the analysis applications than the CAPE distribution, since the lapse rate is just the temperature difference between the two levels while the computation of CAPE requires well-resolved profiles of temperature and moisture. Actually some of stability indices, such as K-index and Total-totals index (Bluestein, 1993), reflect the temperature lapse rate between the lowlevel and the middle-level of the troposphere. The existing observational dataset can be reorganized by the lapse rate or related stability indices. It 
should be noted that the present experiments were initialized with a horizontally homogeneous basic state. Horizontal variability and gradient in the environmental basic state will obscure the effects of lapse rate presented in this study. In spite of this restriction, moist convection should be regulated by the static stability.

The other implication from this study is that precipitation characteristics in a future climate under global warming may be described by the static stability. There are studies that indicate that extreme events producing heavy rainfall increase in a global warming climate (Yoshizaki, 2005; Kimoto et al., 2005; Kamiguchi et al., 2006). Stability diagnosis for those climate simulation data should be useful for examining the variation of precipitation characteristics in the simulated climate.

There are still remaining issues on the effects of stability on the structure and intensity of precipitation within MCSs. The role of cloud microphysics processes would be one of them. Specifically, the environmental temperature affects the generation and enhancement of ice-phase water species and thereby influences the precipitation production. In addition, the partitioning of convective versus stratiform precipitation within convective systems should also be considered by relating to the organization mode of convective systems. The convective/stratiform precipitation is partly discussed in Takemi (2007b) by classifying precipitation with strong (greater than $10 \mathrm{~mm} \mathrm{~s}^{-1}$ ) and weak (between $0.1-1 \mathrm{~mm} \mathrm{~s}^{-1}$ ) intensities; it was shown that the area of the strong precipitation is quite sensitive to temperature lapse rate while that of the weak precipitation does not significantly change between the cases with different temperature profiles. However, the convective/stratiform precipitation partitioning in relation to cloud microphysical processes has not been investigated. The effects of cloud microphysics on the production of 
precipitation (both convective and stratiform types) in a given temperature environment requires further investigations.

\section{Acknowledgments}

This research was supported by Grant-in-Aid for Scientific Research 19740287 from Japan Society for the Promotion of Science, and also by the Grant for Joint Research Program 08-31 from the Institute of Low Temperature Science, Hokkaido University. The GFD Dennou Library was used for drawing some of the figures.

\section{References}

Barnes, G. M., Sieckman, K., 1984: The environment of fast- and slowmoving tropical mesoscale convective cloud lines. Mon. Wea. Rev., 112, $1782-1794$.

Bluestein, H. B., 1993: Synoptic-Dynamic Meteorology in Midlatitudes, Vol. II, Oxford University Press, 594 pp.

Bluestein, H. B., Jain, M. H., 1985: Formation of mesoscale lines of precipitation: Severe squall lines in Oklahoma during the spring. J. Atmos. Sci., $42,1711-1732$.

Cohen, A. E., Coniglio, M. C., Corfidi, S. F., Corfidi, S. J., 2007: Discrimination of mesoscale convective system environment using sounding observations. Wea. Forecasting, 22, 1045-1062.

Deardorff, J. W., 1980: Stratocumulus-capped mixed layers derived from a three-dimensional model. Bound.-Layer Meteor., 18, 495-527. 
Emanuel, K. A., 1994: Atmospheric Convection, Oxford University Press, $580 \mathrm{pp}$.

Fovell, R. G., Ogura, Y., 1989: Effects of vertical wind shear on numerically simulated multicell storm structure. J. Atmos. Sci., 46, 3144-3176.

Fovell, R. G., Ogura, Y., 1988: Numerical simulation of a midlatitude squall line in two dimensions. J. Atmos. Sci., 45, 3846-3879.

Hong, S.-Y., Lim, J.-O. J., 2006: The WRF single-moment 6-class microphysics scheme. J. Korean Meteor. Soc., 42, 129-151.

Hong, S.-Y., Dudhia, J., Chen, S.-H., 2004: A revised approach to icemicrophysical processes for the bulk parameterization of cloud and precipitation. Mon. Wea. Rev., 132, 103-120.

Houston, A. L., Niyogi, D., 2007: The sensitivity of convective initiation to the lapse rate of the active cloud-bearing layer. Mon. Wea. Rev., 135, 3013-3032.

Houze, R. A., Jr., Smull, B. F., Dodge, P., 1990: Mesoscale organization of springtime rainstorms in Oklahoma. Mon. Wea. Rev., 117, 613-654.

James, R. P., Markowski, P. M., Fritsch, J. M., 2006: Bow echo sensitivity to ambient moisture and cold pool strength. Mon. Wea. Rev., 134, 950-964.

James, R. P., Fritsch, J. M., Markowski, P. M., 2005: Environmental distinction between cellular and slabular convective lines. Mon. Wea. Rev., 133, 2669-2691.

Kamiguchi, K., Kitoh, A., Uchiyama, T., Mizuta, R., Noda, A., 2006: Changes in precipitation-based extremes indices due to global warming 
projected by a global 20-km-mesh atmospheric model. Sci. Online Lett. Atmos., 2, 64-67.

Kimoto, M., Yasutomi, N., Yokoyama, C., Emori, S., 2005: Projected changes in precipitation characteristics around Japan under the global warming. Sci. Online Lett. Atmos., 1, 85-88.

Lafore, J. P., Moncrieff, M. W., 1989: A numerical investigation of the organization and interaction of the convective and stratiform regions of tropical squall lines. J. Atmos. Sci., 46, 521-544.

LeMone, M. A., Zipser, E. J., 1980: Cumulonimbus vertical velocity events in GATE. Part I: Diameter, intensity and mass flux. J. Atmos. Sci., 37, $2444-2457$.

LeMone, M. A., Zipser, E. J., Trier, S. B., 1998: The role of environmental shear and thermodynamic conditions in determining the structure and evolution of mesoscale convective systems during TOGA COARE. J. Atmos. Sci., 55, 3493-3518.

Lin, Y.-L., Farley, R. D., Orville, H. D., 1983: Bulk parameterization of the snow field in a cloud model. J. Climate Appl. Meteor., 22, 1065-1092.

McCaul Jr., E. W., Cohen, C., Kirkpatrick, C., 2005: The sensitivity of simulated storm structure, intensity, and precipitation efficiency to environmental temperature. Mon. Wea. Rev., 133, 3015-3037.

Parker, M. D., 2008: Response of simulated squall lines to low-level cooling. J. Atmos. Sci., 65, 1323-1341.

Robe, F. R., Emanuel, K. A., 2001: The effects of vertical wind shear on radiative-convective equilibrium states. J. Atmos. Sci., 58, 1427-1445. 
Rotunno, R., Klemp, J. B., Weisman, M. L., 1988: A theory for strong, long-lived squall lines. J. Atmos. Sci., 45, 463-485.

Rotunno, R., Klemp, J. B., Weisman, M. L., 1990: Comments on “a numerical investigation of the organization and interpretation of the convective and stratiform regions of tropical squall lines". J. Atmos. Sci., 47, 10311033.

Skamarock, W. C., Klemp, J. B., Dudhia, J., Gill, D. O., Barker, D. M., Wang, W., Powers, J. G., 2005: A description of the Advanced Research WRF Version 2. NCAR Tech. Note, NCAR/TN-468+STR, 88 pp.

Takemi, T., 2007a: Environmental stability control of the intensity of squall lines under low-level shear conditions. J. Geophys. Res., 112, D24110, doi:10.1029/2007JD008793.

Takemi, T., 2007b: A sensitivity of squall-line intensity to environmental static stability under various shear and moisture conditions. Atmos. Res., 84, 374-389.

Takemi, T., 2006: Impacts of moisture profile on the evolution and organization of midlatitude squall lines under various shear conditions. Atmos. Res., 82, 37-54.

Takemi, T., Satomura, T., 2000: Numerical experiments on the mechanisms for the development and maintenance of long-lived squall lines in dry environments. J. Atmos. Sci., 57, 1718-1740.

Takemi, T., Hirayama, O., Liu, C., 2004: Factors responsible for the vertical development of tropical oceanic cumulus convection. Geophys. Res. Lett., 31, L11109, doi:10.1029/2004GL020225. 
Thorpe, A. J., Miller, M. J., Moncrieff, M. W., 1982: Two-dimensional convection in non-constant shear: a model of mid-latitude squall lines. Quart. J. Roy. Meteor. Soc., 108, 739-762.

Wang, T.-C. C., Lin, Y.-J., Pasken, R. W., Shen, H., 1990: Characteristics of a subtropical squall line determined from TAMEX dual-Doppler data. Part I: Kinematic structure. J. Atmos. Sci., 47, 2357-2381.

Weisman, M. L., Klemp, J. B., 1982: The dependence of numerically simulated convective storms on vertical wind shear and buoyancy. Mon. Wea. Rev., 110, 504-520.

Weisman, M. L., Rotunno, R., 2004: "A theory for strong long-lived squall lines" revisited. J. Atmos. Sci., 61, 361-382.

Weisman, M. L., Klemp, J. B., Rotunno, R., 1988: Structure and evolution of numerically simulated squall lines. J. Atmos. Sci., 45, 1990-2013.

Yoneyama, K., 2003: Moisture variability over the tropical western Pacific Ocean. J. Meteor. Soc. Japan, 81, 317-337.

Yoshizaki, M., Muroi, C., Kanada, S., Wakazuki, Y., Yasunaga, K., Hashimoto, A., Kato, T., Kurihara, K., Noda, A., Kusunoki, S., 2005: Changes of Baiu (Mei-yu) frontal activity in the global warming climate simulated by a non-hydrostatic regional model. Sci. Online Lett. Atmos., $1,25-28$. 
Table 1: List of numerical experiments. $R H_{s f c}$ and PWC refer to the relative humidity (\%) at the surface and precipitable water content $\left(\mathrm{kg} \mathrm{m}^{-2}\right)$, respectively.

\begin{tabular}{lllcccc}
\hline Series & Case & $\theta_{t r}$ & CAPE & $q_{v 0}$ & $R H_{s f c}$ & PWC \\
\hline C17 & C17T43 & 343 & 1734 & 13.1 & 60 & 44.4 \\
& C17T48 & 348 & 1767 & 14.5 & 66 & 47.9 \\
& C17T53 & 353 & 1772 & 16.0 & 73 & 51.3 \\
& C17T58 & 358 & 1772 & 17.7 & 81 & 54.7 \\
\hline \multirow{2}{*}{ 10 } & C10T43 & 343 & 1086 & 12.1 & 55 & 42.8 \\
& C10T48 & 348 & 1061 & 13.2 & 60 & 46.2 \\
& C10T53 & 353 & 1064 & 14.5 & 66 & 49.8 \\
& C10T58 & 358 & 1081 & 16.0 & 73 & 53.4 \\
\hline \multirow{2}{*}{ C26 } & C26T43 & 343 & 2634 & 14.4 & 66 & 46.0 \\
& C26T48 & 348 & 2668 & 16.0 & 73 & 49.4 \\
& C26T53 & 353 & 2648 & 17.7 & 81 & 52.5 \\
& C26T58 & 358 & 2633 & 19.0 & 87 & 55.2 \\
\hline
\end{tabular}


Table 2: The temporal means of the percentage areas (\%) of total precipitation (greater than $1 \mathrm{~mm} \mathrm{~h}^{-1}$ ) and intense precipitation (greater than $10 \mathrm{~mm} \mathrm{~h}^{-1}$ ) over the analysis area.

\begin{tabular}{|c|c|c|c|c|c|}
\hline \multirow[b]{2}{*}{ Series } & \multirow[b]{2}{*}{ Case } & \multicolumn{2}{|c|}{ Weak Shear Cases } & \multicolumn{2}{|c|}{ Strong Shear Cases } \\
\hline & & Total & Intense & Total & Intense \\
\hline \multirow[t]{4}{*}{$\mathrm{C} 17$} & $\mathrm{C} 17 \mathrm{~T} 43$ & 63.9 & 25.5 & 44.9 & 30.9 \\
\hline & $\mathrm{C} 17 \mathrm{~T} 48$ & 55.1 & 23.3 & 35.0 & 23.6 \\
\hline & $\mathrm{C} 17 \mathrm{~T} 53$ & 39.1 & 18.5 & 24.5 & 6.9 \\
\hline & C17T58 & 19.3 & 6.9 & 20.3 & 6.7 \\
\hline \multirow[t]{4}{*}{$\mathrm{C} 10$} & $\mathrm{C} 10 \mathrm{~T} 43$ & 45.2 & 16.9 & 30.8 & 21.0 \\
\hline & $\mathrm{C} 10 \mathrm{~T} 48$ & 39.9 & 15.7 & 20.6 & 12.6 \\
\hline & C10T53 & 26.7 & 10.1 & 7.1 & 1.8 \\
\hline & C10T58 & 7.5 & 2.4 & 4.1 & 1.0 \\
\hline \multirow[t]{4}{*}{$\mathrm{C} 26$} & $\mathrm{C} 26 \mathrm{~T} 43$ & 82.0 & 33.9 & 56.3 & 39.4 \\
\hline & $\mathrm{C} 26 \mathrm{~T} 48$ & 68.7 & 30.0 & 45.8 & 31.5 \\
\hline & $\mathrm{C} 26 \mathrm{~T} 53$ & 53.7 & 25.0 & 44.6 & 20.6 \\
\hline & C26T58 & 33.8 & 14.2 & 28.8 & 10.4 \\
\hline
\end{tabular}




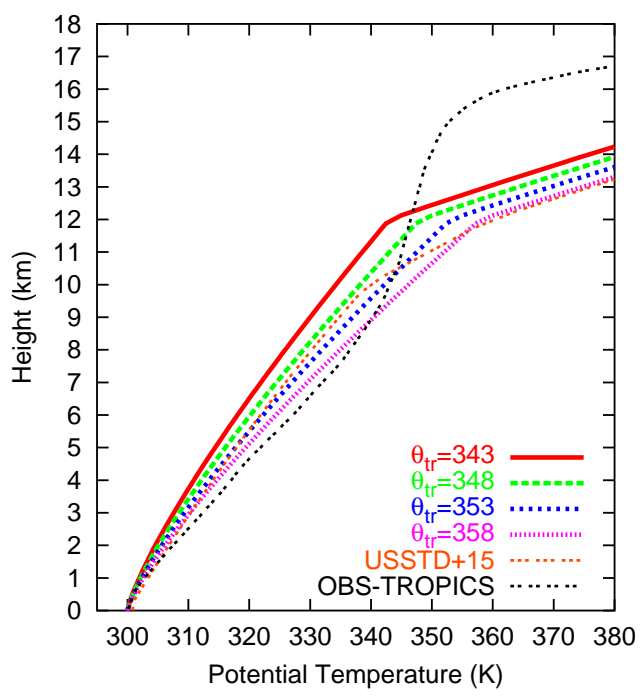

Figure 1: The vertical profiles of environmental potential temperature for the numerical experiments with different $\theta_{t r}$ values $(343,348,353$, and $358 \mathrm{~K})$. The profiles of the Unites States Standard Atmosphere (USSTD+15) (with $15 \mathrm{~K}$ added) and observations in the tropical western Pacific (OBS-TROPICS) are also plotted for comparison. 


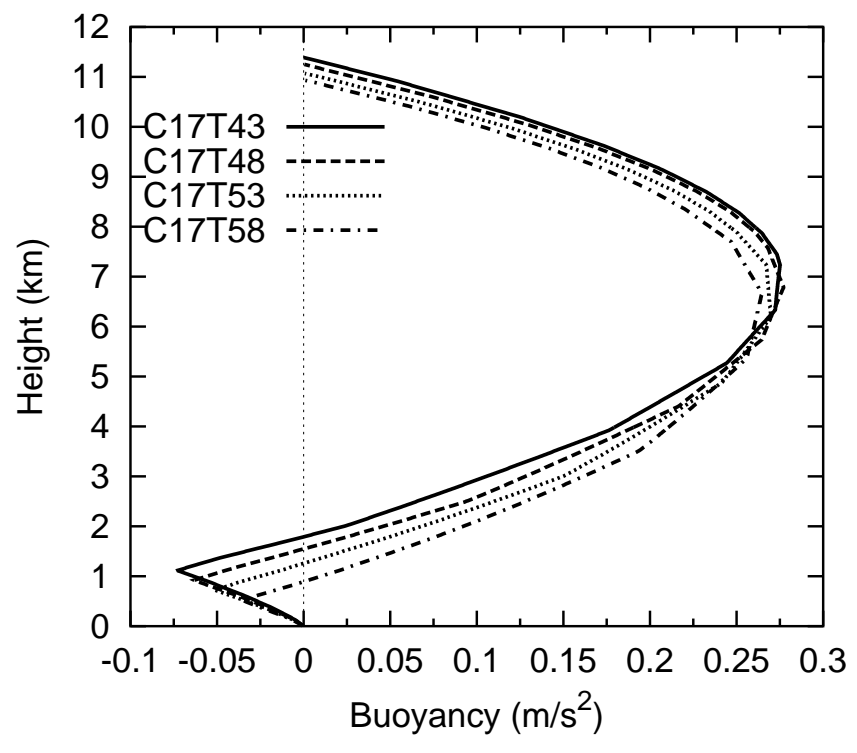

Figure 2: The vertical profiles of buoyancy $\left(\mathrm{m} \mathrm{s}^{-2}\right)$ for parcels originated at the lowest level in different $\theta_{t r}$ cases. 


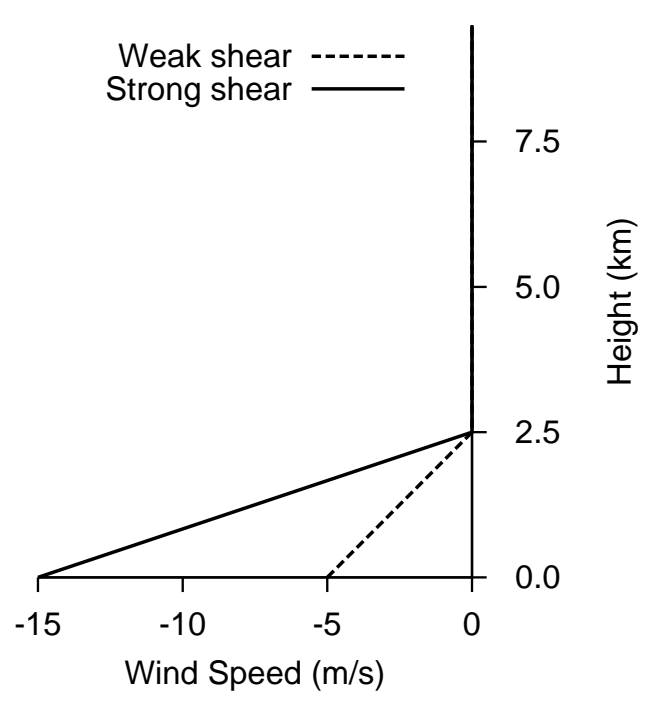

Figure 3: The vertical profiles of environmental wind for the cases with the weak and the strong shear. 

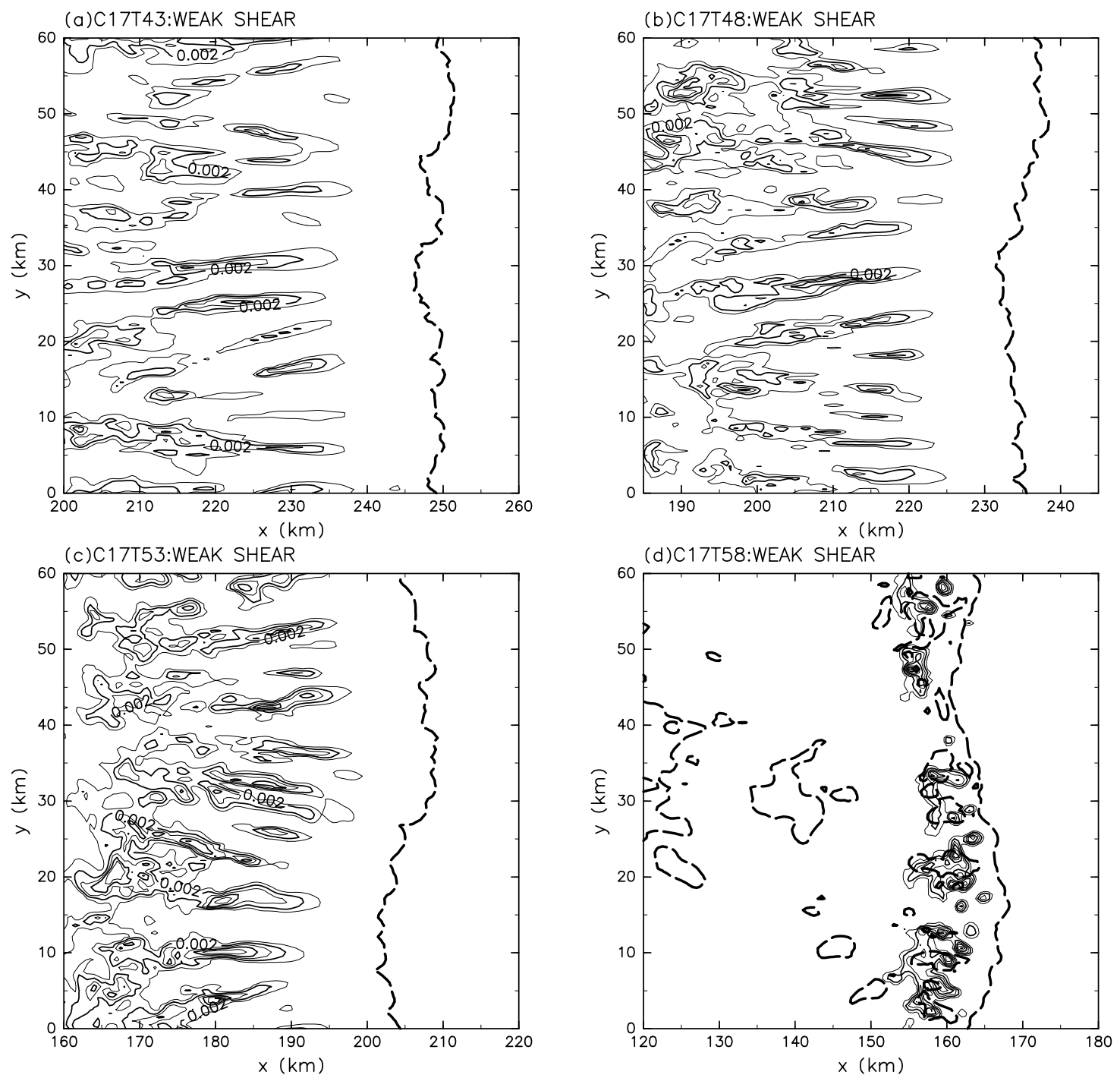

Figure 4: Horizontal cross section of total water condensation (i.e., cloud and precipitation) mixing ratio at the $3-\mathrm{km}$ height (solid contours) and the surface gust front (dashed line) at $4 \mathrm{~h}$ for (a) C17T43, (b) C17T48, (c) C17T53, and (d) C17T58 with the weak shear. The contour interval is $1.0 \times 10^{-3} \mathrm{~g} \mathrm{~kg}^{-1}$. 

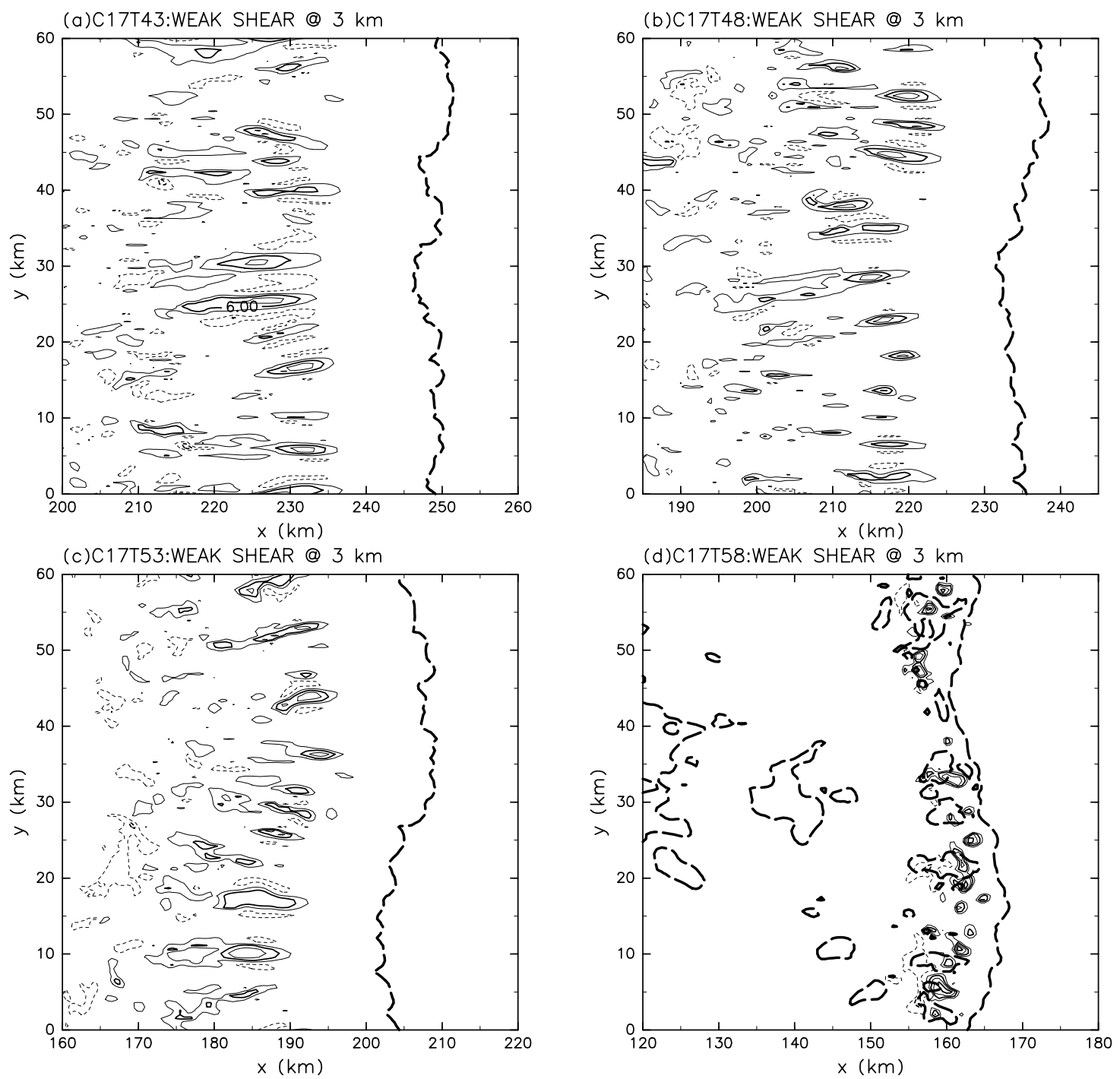

Figure 5: The same as Fig. 4, except for vertical velocity (contoured at $3-\mathrm{m} \mathrm{s}^{-1}$ interval). 

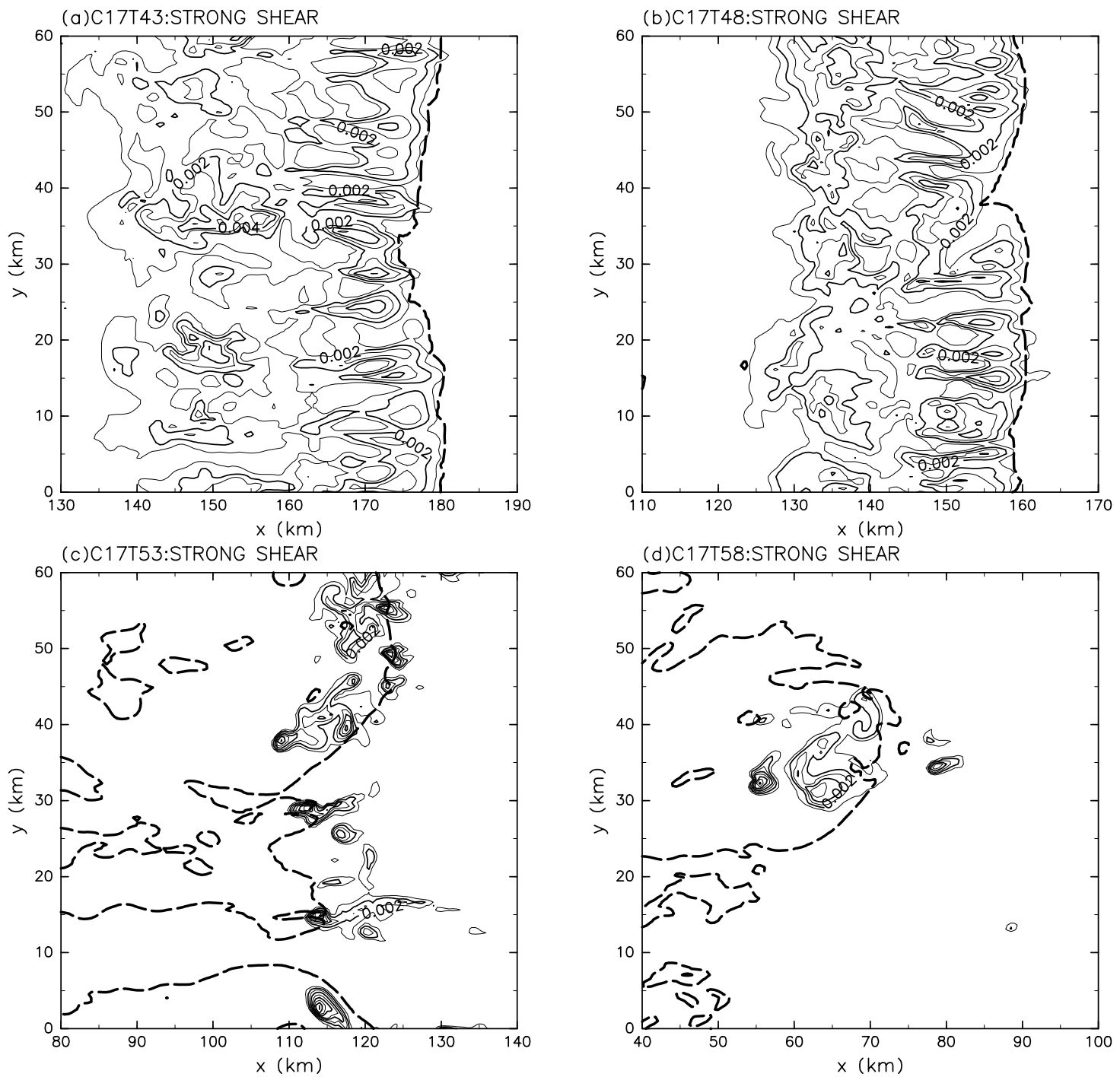

Figure 6: The same as Fig. 4, except for the strong-shear cases. 

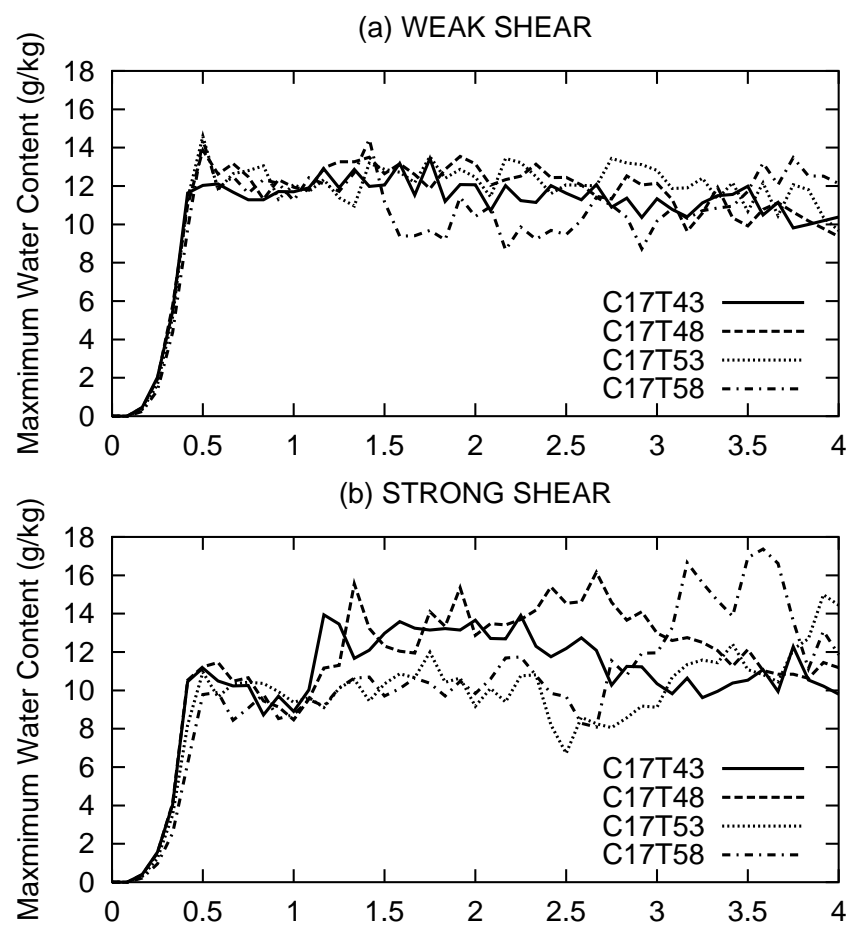

Figure 7: Time series of the maximum water condensation mixing ratio in the computational domain for (a) the weak-shear (shown in Fig. 4) and (b) the strong-shear cases (shown in Fig. 6). 

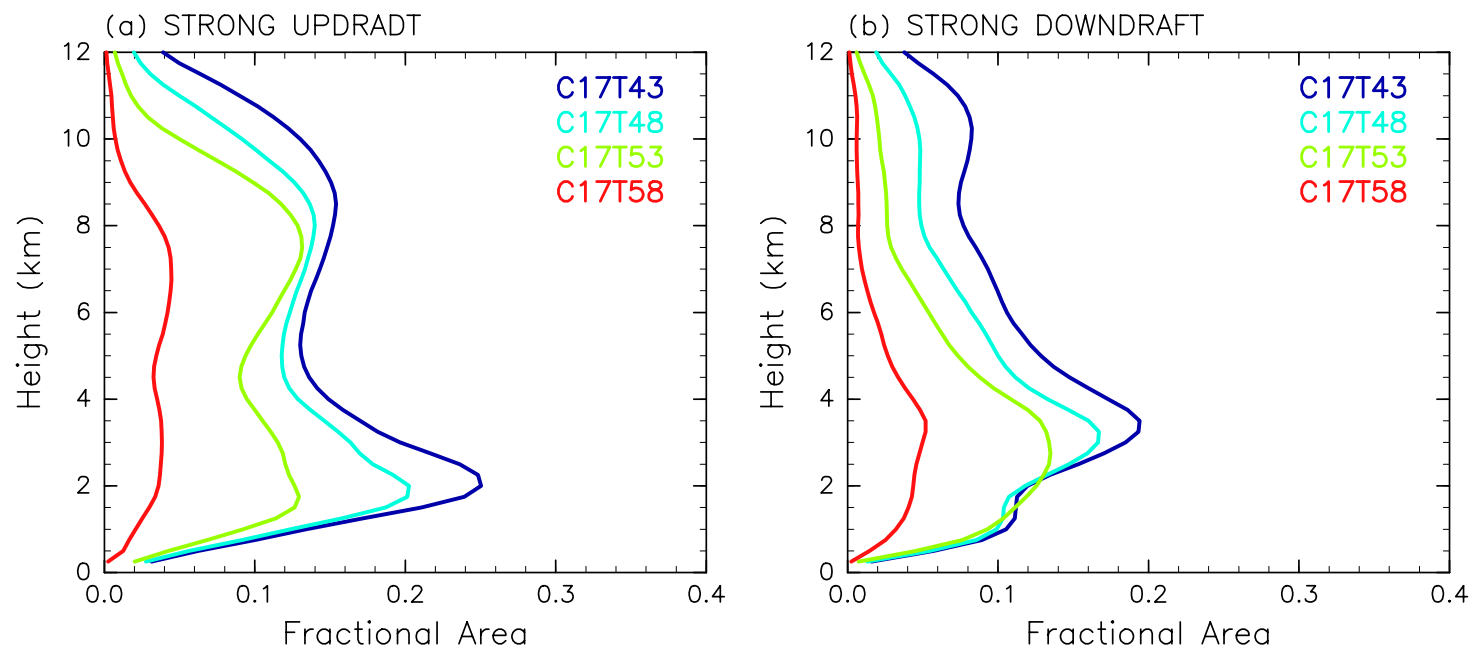

Figure 8: The temporal averaged vertical profiles of the fractional area of (a) strong updraft and (b) strong downdraft for the weak-shear C17 cases. 

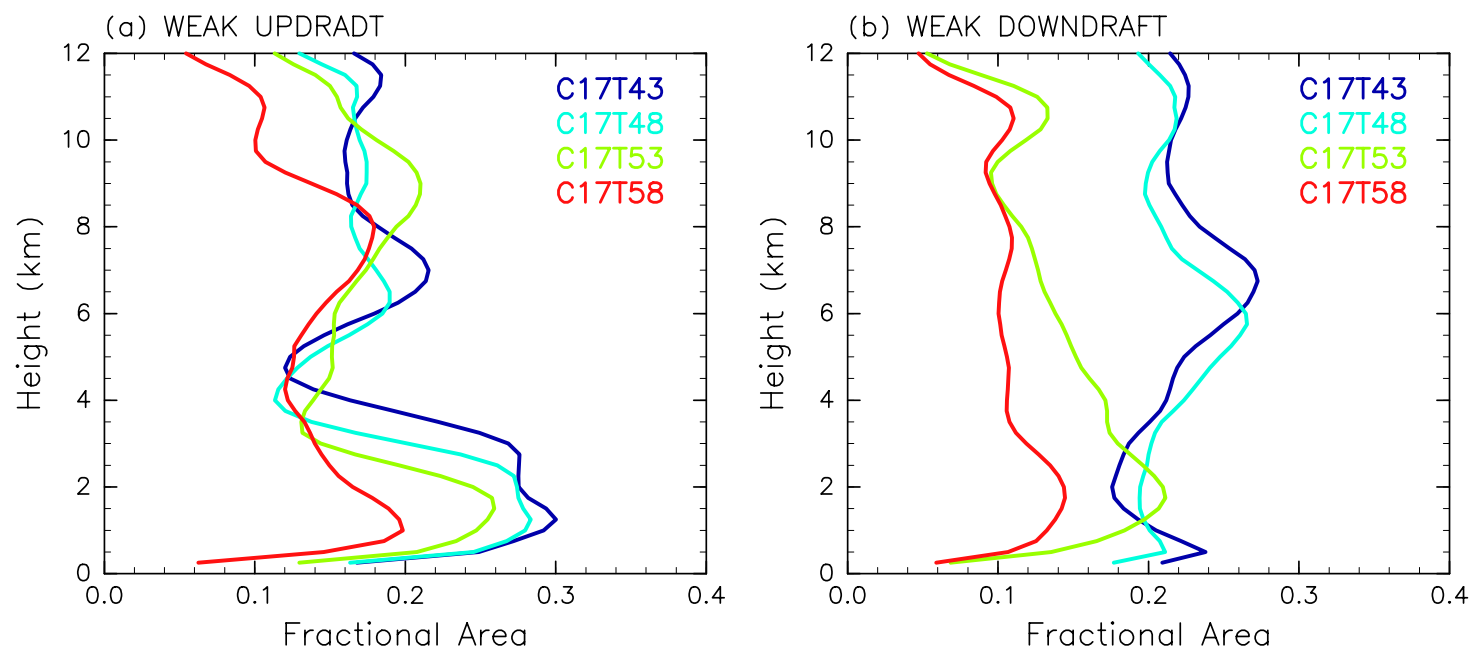

Figure 9: The same as Fig. 8, except for the weak updraft and downdraft. 
a) WEAK SHEAR

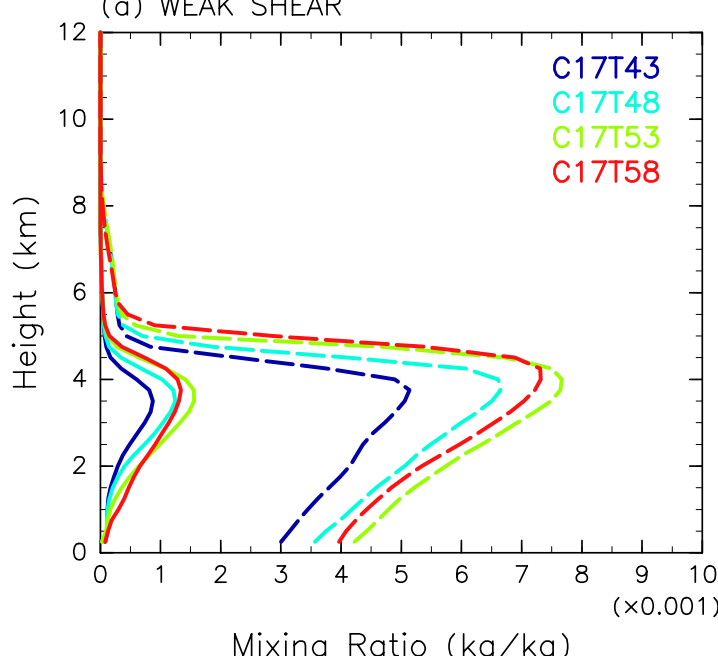

(b) STRONG SHEAR

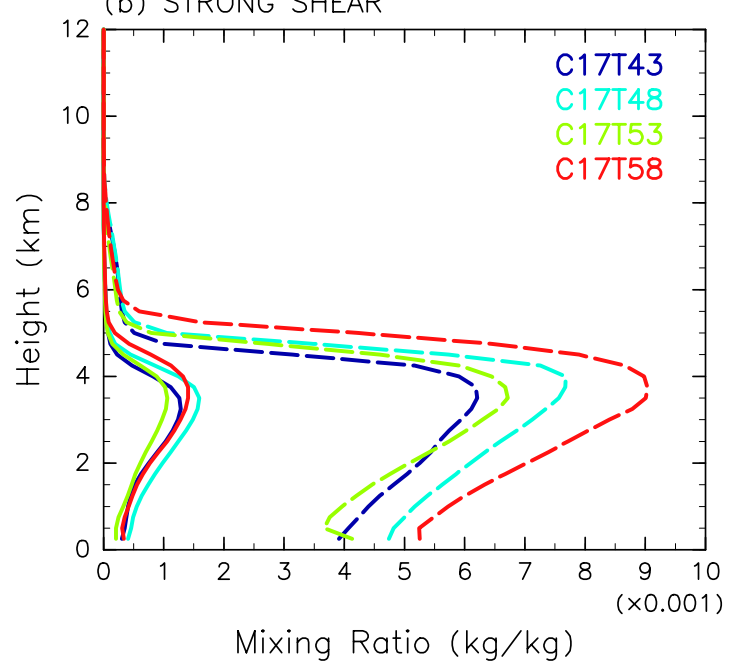

Figure 10: The vertical profiles of the temporal averages of the area mean (solid line) and maximum (dashed line) rainwater mixing ratio at strong updraft locations for the C17 cases with (a) the weak shear and (b) the strong shear. 

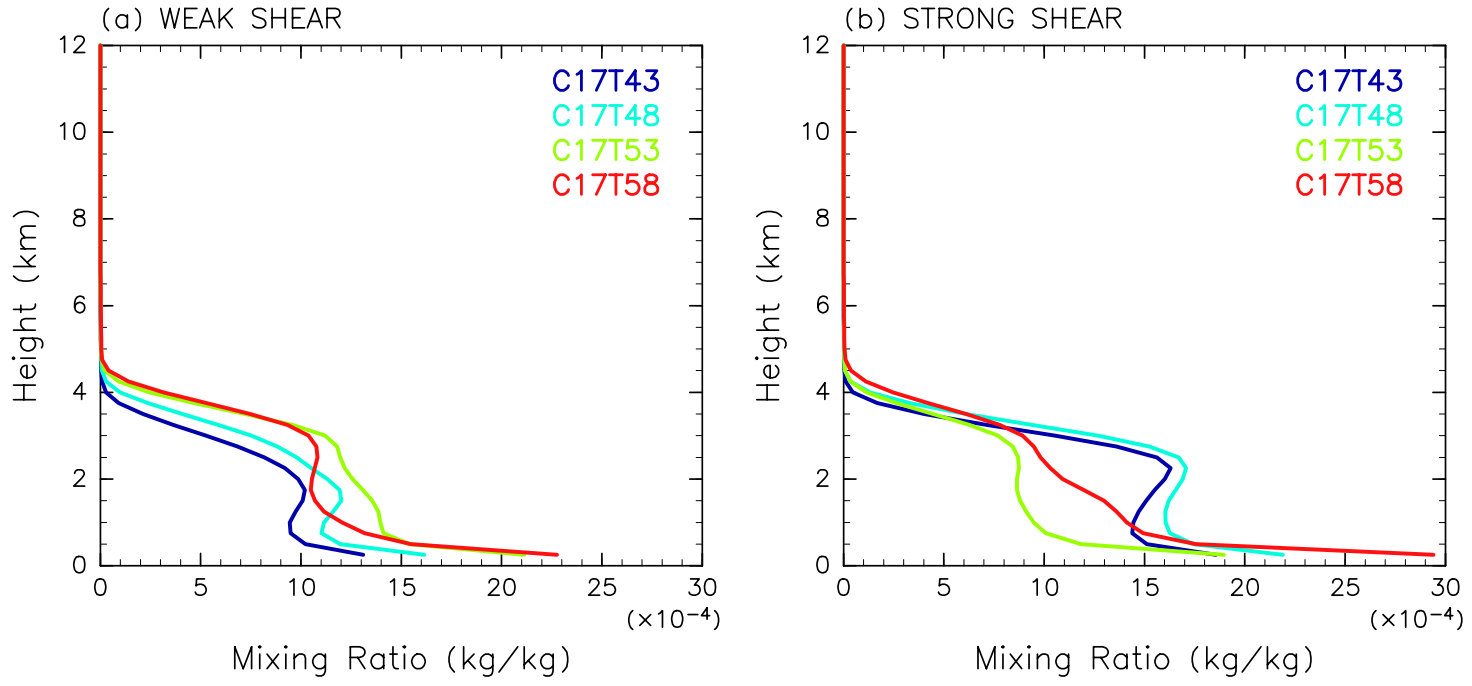

Figure 11: The vertical profiles of the temporal and area means of rainwater mixing ratio at strong downdraft locations for the $\mathrm{C} 17$ cases with (a) the weak shear and (b) the strong shear. Note that the range of the horizontal axis is smaller than that shown in Fig. 10. 


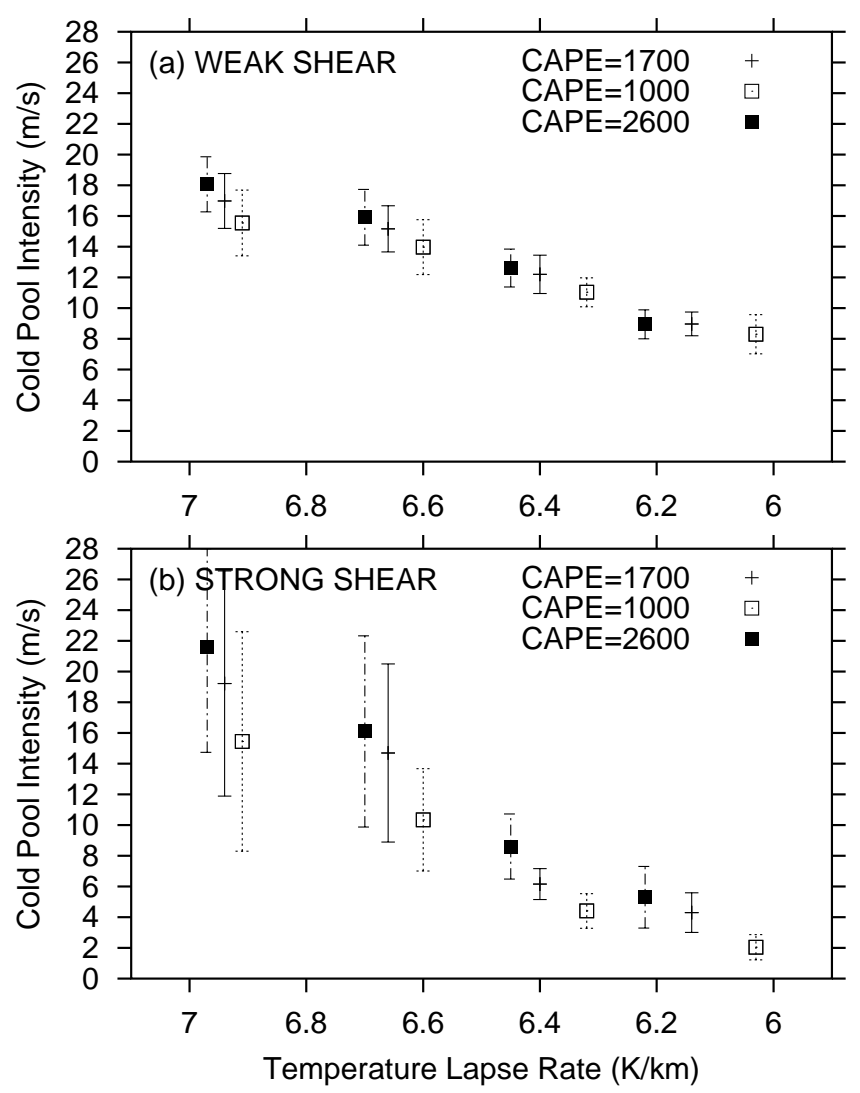

Figure 12: The mean (symbols) and standard deviation (error bars) of the intensity of cold pool during the period of $1-4 \mathrm{~h}$ for the three CAPE series with (a) the weak shear and (b) the strong shear. 

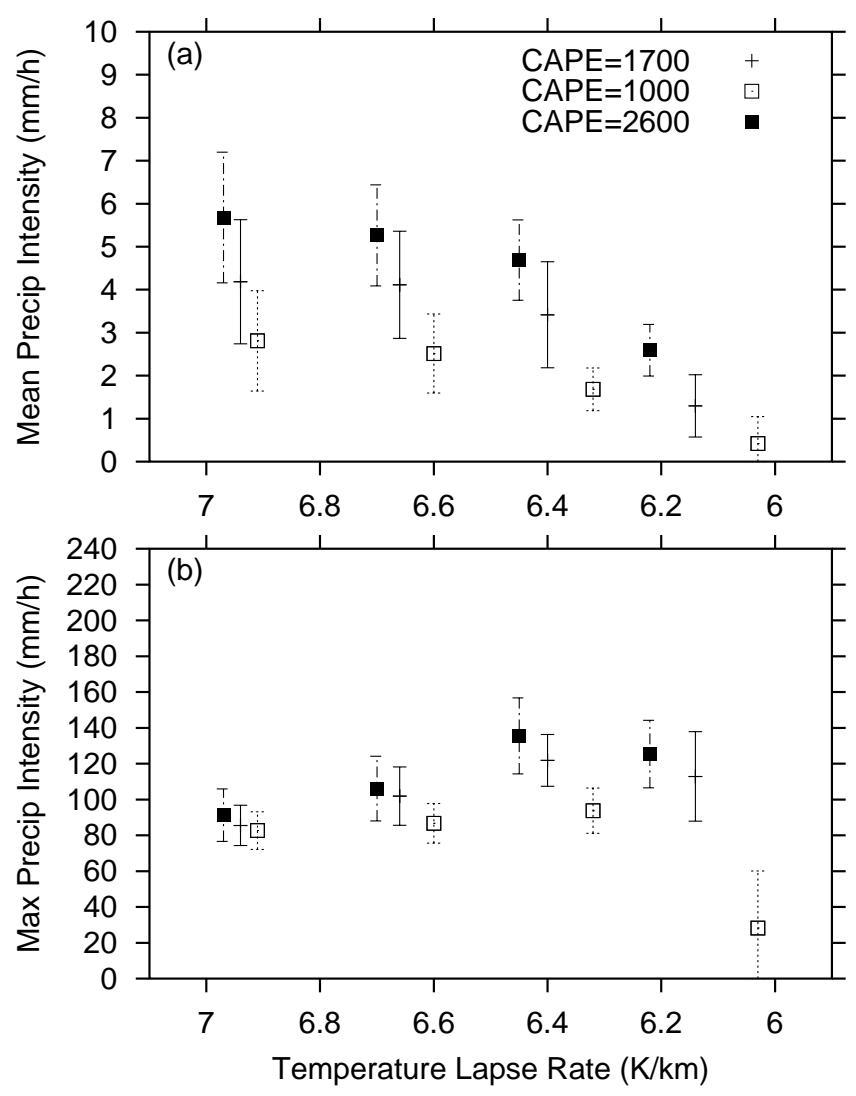

Figure 13: The mean (symbols) and standard deviation (error bars) from the time series of precipitation intensity at the surface over the analysis area during the period of 1-4 $\mathrm{h}$ for the weak-shear cases: (a) the area means and (b) the maxima. 

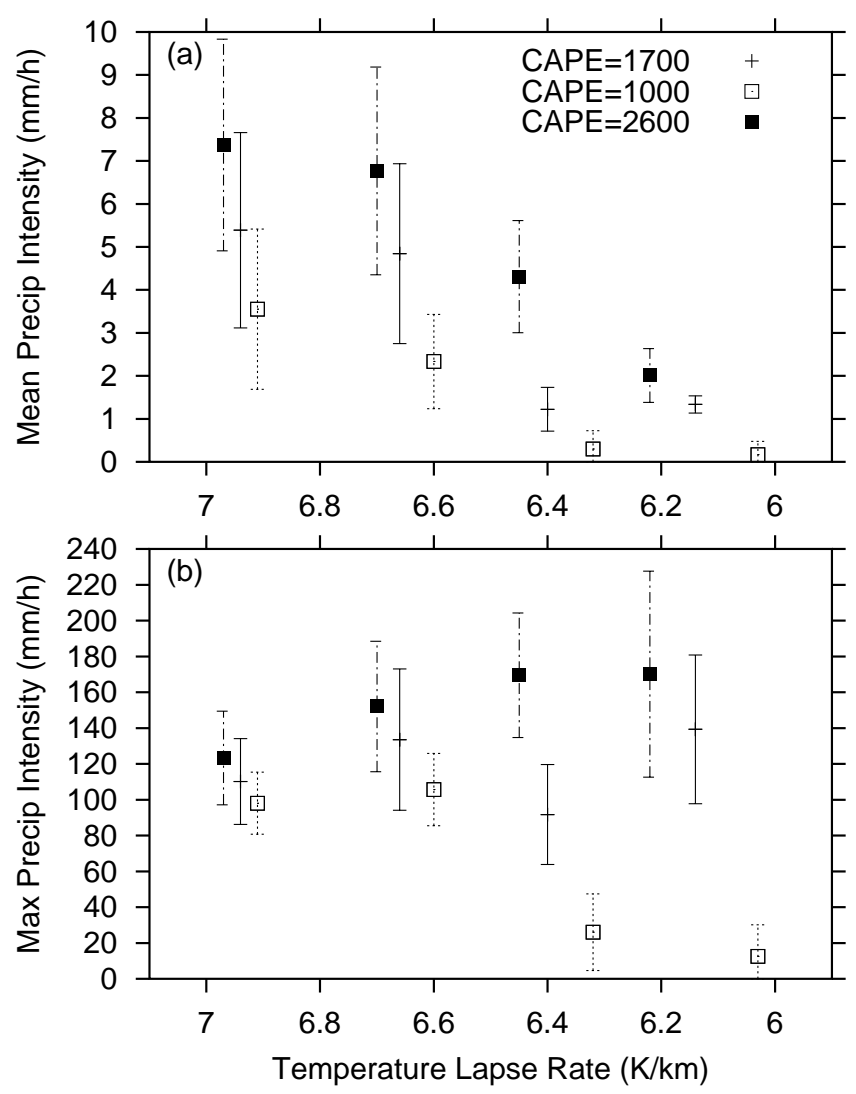

Figure 14: The same as Fig. 13, except for the strong-shear cases. 

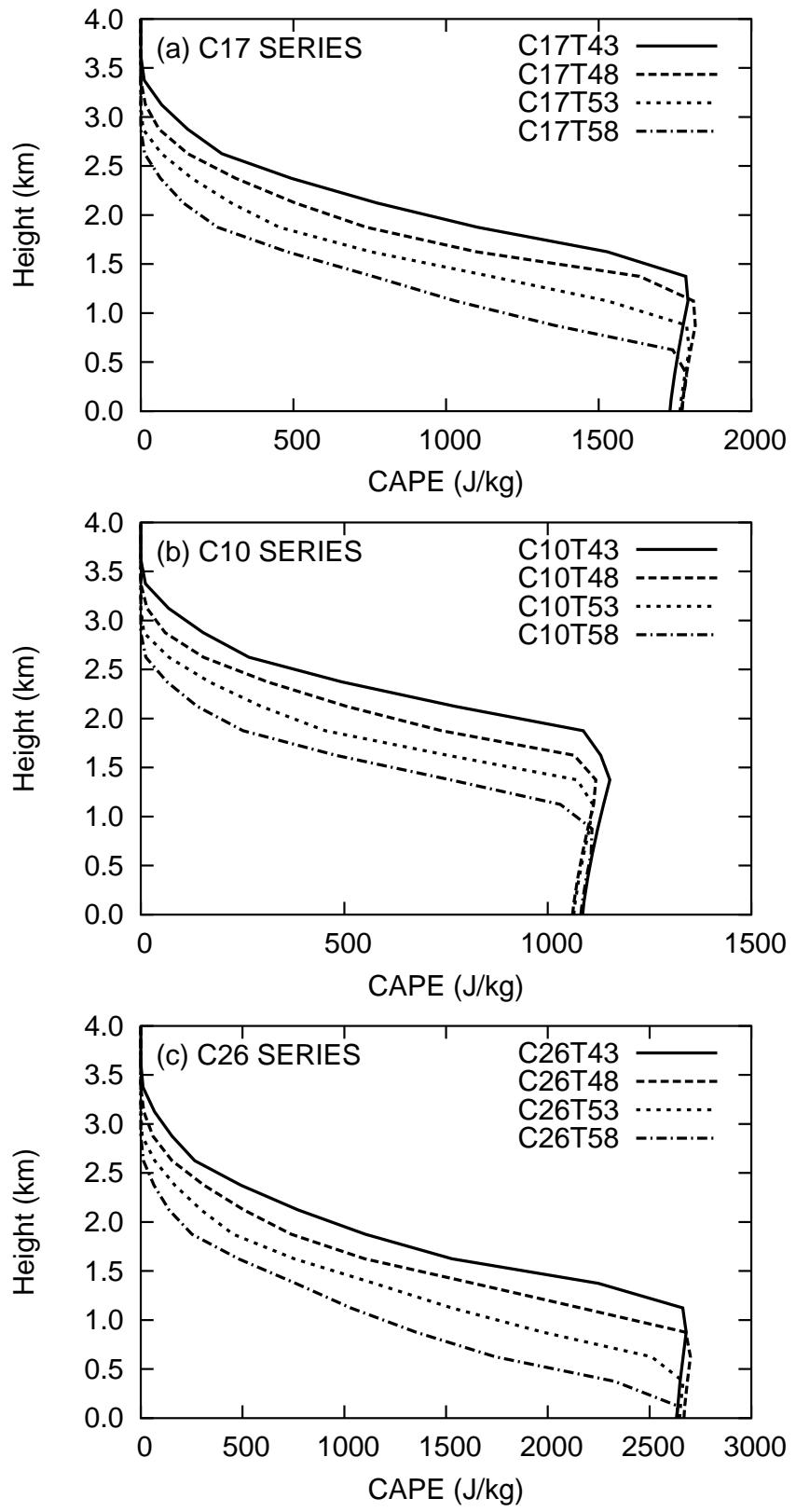

Figure 15: The vertical distribution of CAPE for parcels originating at each height. 